\title{
Using a Turnkey Automated System to Support Collection Assessment
}

\author{
Robert K. Baker
}

A review of the professional literature reveals that librarians have an increased commitment to the collection assessment process as a means of describing collection strengths and weaknesses. Numerous authors point to the many benefits to be realized through assessment, but also acknowledge the labor-intensiveness of the activity. This article details how a small community college library is making use of a turnkey automated system (by Dynix) and a microcomputerbased database program to generate special reports and statistical profiles to support an ongoing collection assessment project.

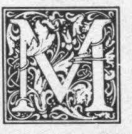

ost librarians who have written about collection assessment in recent years have generally acknowledged that automation plays an important role in providing ever more accurate statistics on the nature of the collection and of its use. But little has been written about how a turnkey automated system can increase the costeffectiveness and manageability of the collection assessment process, particularly in a smaller library with limited staffing. Such is the purpose of this article.

\section{BACKGROUND TO ASSESSMENT}

Lower Columbia College Library (LCC) is one of the smallest libraries in the Washington state community college system, with a collection size of 29,730 volumes, a professional staff of 1.66 FTE, and a classified staff of 2.75 FTE. The Library's initial experience with collection assessment began in 1984, when the Fred Meyer Charitable Trust (based in Portland, Oregon), established "LIRN," the "Library and Information Resources for the Northwest" program. The goal of the program was to "assist libraries in improving ac- cess to information [. . . ] thereby enhancing the educational, economic, and civic development of the region. ${ }^{\prime 1}$ Libraries throughout the Pacific Northwest were invited to participate in the principal LIRN program activity: collection assessment based on the RLG "conspectus" model as implemented by the Alaska Statewide Collection Development project. As a tool for subject analysis, "The conspectus is a method which enables libraries to assess their collections on a subject by subject basis according to standardized criteria and to describe collection strengths and weaknesses."'2

The LCC Library provided the LIRN project with profiles of six subject divisions. Not surprisingly given the size of the Library's collections, virtually all of the subject areas assessed were at the lowest end of the indicator spectrum as used by the LIRN project: "0: Out of scope," "1a: Minimal, with uneven coverage," or "1b: Minimal, but chosen well." 3 By the end of our assessment activities with LIRN, we were intrigued with the assessment process as well as with the collection-level indicators used in the con-

Robert K. Baker is Assistant Vice Chancellor for Information Services at Pima Community College, Tucson, Arizona 85709. 
spectus. Indeed, we believed that the conspectus approach to collection assessment might just be the strategic technology we needed to communicate our collection development needs to faculty and administrators at the college. We were also concerned that the size of our staff would make the labor-intensive ongoing collection assessment activity difficult to continue.

But in 1986, the Library received a LSCA Title III grant from the Washington State Library Commission. The grant allowed the LCC Library to share a Dynix integrated library computer system that had been installed at neighboring Longview Public Library in 1985. This arrangement offered the potential to gather statistics that had been heretofore unavailable. At the time of installation, LCC contracted with Dynix to use all of the modules that had been purchased by Longview Public Library, among them circulation, online public access, and cataloging. Also included was Dynix's "RECALL" module that allows libraries to write simple English language-like statements at the level of the computer's PICK operating system. Such statements can extract-without programmer assistance-data and statistics gathered by other modules such as cataloging or circulation. The potential for the Dynix system to support collection assessment was clear even during the installation year, but could not be realized until after at least a year's worth of use statistics had been gathered.

\section{A COLLECTION DEVELOPMENT POLICY}

As a prelude to continuing the assessment program, the library's faculty advisory committee worked on developing a formal collection development policy during the 1987-88 academic year. Among other things, the policy was meant to serve as the impetus for beginning to rebuild a book collection that had suffered from years of underfunding. The policy, approved by that committee in May 1988, stipulated an important guiding principle: that "additions to the collection should be selected primarily to be useful to-and used by-students. The college wishes to build a 'student-centered' LRC collection."'4 The college administration approved a modest addition of $\$ 3,500$ to the regular materials budget of $\$ 37,438$ to support assessment activity.

Given the newly adopted principle, and the need to engender faculty support for building the collections, we determined that we wanted to broaden the "collection-centered" LIRN conspectus approach to incorporate more "clientcentered" data into our assessments so that we could show faculty how students used the collection. ${ }^{5,6}$ Much of this clientcentered data was available in the automated system.

\section{CUSTOMIZED STATISTICS ON THE AUTOMATED SYSTEM}

The library routinely gathers materials from tables, carrels, and reshelving shelves, and checks them out to a special "in-house user" patron type to gather statistics on in-library use of materials before reshelving. With over two years of both in-house and lending statistics for the regular Dewey-classified circulating collection as well as the reference collection, it was time to begin to find ways to use our automated system to support some kind of assessment process. Of course, the turnkey system as installed offered menuselectable statistical reports that showed the circulation of items within various call number ranges. We could also easily determine the number of items in specific parts of the library collection. But we were interested in gathering more in-depth collection profile information which we could present to instructional faculty.

As already noted, the Dynix system provides clients with a special moduleRECALL-whose purpose it is to enable the gathering of data and statistics beyond those included in the menu-selectable reports already supported in the system's functional modules. Of course, this kind of functionality is not unique to Dynix. Figure 1, which shows the top ten automated system installers in academic libraries in 1988, reveals that many of today's vendors provide similar report generation capabilities. ${ }^{7,8}$

Among the uses typically found for RE- 
CALL at Dynix installations are listings of patrons owing excessive fines; the number of items overdue at any given point in time; sorted lists of patrons residing in particular zip codes; and the number of items within various categories of the collection. Indeed, few factors limit the kinds of data that can be recovered-or how the data can be presented-using RECALL.

Indeed, we believed that the conspectus approach to collection assessment might just be the strategic technology we needed to communicate our collection development needs to faculty and administrators at the college.

After some ten hours of professional time, as well as several telephone calls to the support staff at Dynix, we developed and completed testing on five RECALL programs designed to provide us with the kinds of data that would be more useful to our assessment project. These in-house programs are executed sequentially by the computer, and, having been saved to disk, can be run anytime we need to do an assessment of a different subject or topic area. Text in the programs need be modified only slightly, a process consuming no more than five minutes per topic area.

The first program selects items in the library collection within a call number range (e.g., 610-619, the health sciences in Dewey) and saves the selections to disk as a named list. This saved listing is then retrieved by a subsequent RECALL program and is further broken down and saved as smaller "topic" listings (e.g., 610, medicine). The next two programs select each of the saved topic lists (as well as the broader subject listing) and count the following:

- the number of volumes actually used since the computer system was installed;

- the total number of circulations in the topic area since installation;

- the number of holdings with collection codes for nonfiction (including oversize, some reserve collection items, and items "in process"');

- the number of holdings with collection codes for reference (including atlases and indexes);

- the number of holdings with collection codes for audiovisual materials; and

- the number of holdings published up to and including 1978, between 1979 and 1982 inclusive, and from 1983 on.

A resident RECALL specialist (and Customer Support Manager) at Dynix, Gretchen Freeman, created a special dictionary of publication dates to circumvent the inconsistencies that would be encountered in subfield " $\mathrm{d}$ " of the imprint field of the MARC record. The dictionary strips away any extraneous characters (such as [ or ${ }^{\odot}$ ) to leave a data element composed of the first four numeric characters encountered in the subfield. Counts of publication dates in this special dictionary do register some anomalous statistics because of the nature of publication dates in serially published items, but the Library was willing to accept this.

The final program prints out a saved list. This printout reveals all library holdings regardless of location in the collection: similar to a shelflist, but sorted by highest number of uses. Included in the listing is the number of uses of the item, the call number, the collection code (e.g., nonfiction, reference, oversize), title, author, and publication date.

\section{MICROCOMPUTER SUPPORT FOR STATISTICAL GATHERING}

The various counts from the RECALL programs are manually entered into a database established on a MS-DOS microcomputer. The database was created using QEA Version 3.0, a "flat file" database manager with word processing and mailmerge capabilities from Symantec Corporation. The database calculates percentages of volumes published between certain dates and circulation or other use percentages. The database also stores the names of faculty members (or departments) who will be contacted with the information. The design of the database consumed approximately six to eight 


\begin{tabular}{|c|c|}
\hline Vendor & Report Generation Characteristics \\
\hline Carlyle Systems & $\begin{array}{l}\text { Carlyle's report writer, called INGRES, can retrieve data elements for } \\
\text { simple or complex reports; includes document and text formatting } \\
\text { abilities and arithmetic capabilities; can dynamically change report } \\
\text { parameters each time the report is printed. }\end{array}$ \\
\hline $\begin{array}{l}\text { Data Research } \\
\text { Associates }\end{array}$ & $\begin{array}{l}\text { DRA's optional module-UserBase-runs on the VAX/VMS family of } \\
\text { computers. It fully supports the MARC format, maintains a data dic- } \\
\text { tionary, and generates and maintains data entry and transaction screens. } \\
\text { It can also calculate, process, or manipulate data, and generates menus, } \\
\text { reports, forms, letters, and labels. }\end{array}$ \\
\hline Geac Computers & $\begin{array}{l}\text { Both Geac systems (ADVANCE, a PICK-based system for small- } \\
\text { medium libraries, and GLIS for larger systems) feature flexible report } \\
\text { generators which can extract information from any field or combination } \\
\text { of fields, with content and format controlled by the library. ADVANCE } \\
\text { also uses the RECALL language found on the Dynix system. In the } \\
\text { future, ADVANCE will contain a more sophisticated and user friendly } \\
\text { report generation interface. }\end{array}$ \\
\hline IBM/DOBIS & $\begin{array}{l}\text { While this system does not have a report generator per se, some clients } \\
\text { are generating reports beyond the typical management reports from a } \\
\text { DOBIS/Leuven database. The approaches include use of the journal or } \\
\text { transaction data, and extraction of required fields from the DOBIS } \\
\text { database itself. }\end{array}$ \\
\hline Innovative Interfaces & $\begin{array}{l}\text { The INNOPAC report generator resides in the Management Information } \\
\text { subsystem. It can retrieve any data elements previously defined on the } \\
\text { Innovative Interfaces system (including full MARC fixed and variable } \\
\text { fields), and is sortable in any form. INNOPAC supports Boolean } \\
\text { operators. }\end{array}$ \\
\hline NOTIS & $\begin{array}{l}\text { NOTIS installations presently produce customized reports using the } \\
\text { SAS report writer package from the SAS Institute (and clients typically } \\
\text { share the programs amongst themselves). A new optional module- } \\
\text { NOTIS Report Writer-which provides a "user-friendly" online } \\
\text { interface to SAS for designing customized reports will be available for } \\
\text { purchase in the fourth quarter of } 1990 \text {. }\end{array}$ \\
\hline OCLC Local Systems & $\begin{array}{l}\text { The LS/2000 system provides collection assessment capabilities through } \\
\text { a variety of off-line printed reports in its Administrative Subsystem. } \\
\text { The reports can be sorted and/or limited by one or more fields of } \\
\text { information. Among the reports offered: items in circulation; low } \\
\text { circulating items; purchase alert by circulation; or purchase alert by hold. }\end{array}$ \\
\hline UNISYS & $\begin{array}{l}\text { The UNISYS CIRC system can maintain statistics for call number } \\
\text { schedules, and clients can create schedules for up to four collections or } \\
\text { parts of a collection with up to sixty ranges in each. Clients may also } \\
\text { create up to } 500 \text { statistical classes for either item or patron types for use } \\
\text { in reports. }\end{array}$ \\
\hline VTLS & $\begin{array}{l}\text { The VTLS on-line reporting subsystem uses severa! parameters to select } \\
\text { records, including up to five different call number ranges, record } \\
\text { format, language code, publication date ranges, and location. In } \\
\text { addition, the VTLS-89/Hewlett-Packard product has a report writing } \\
\text { program called HP Business Report Writer that allows any data item in } \\
\text { the database to be used in generating reports. }\end{array}$ \\
\hline
\end{tabular}

FIGURE 1

Vendor/Report Generation Characteristic Table 
hours of professional time.

Once the data has been entered into $Q \mathcal{E} A$ and printed out in RECALLgenerated title listings, the database program then prints the form letters to faculty via the mail-merge function. These letters accompany the printouts. The process of entering the data and printing out mailmerge letters generally consumes no more than five to ten minutes per topic area. A sample letter based on the data from a health science assessment appears below. The " " marks indicate where the "mailmerge" elements are inserted by $Q \mathcal{E} A$; these marks do not, of course, appear in the actual faculty letters. The letter reads:

"Date of printing"

TO: "Nursing Department Faculty"

FR: Library

RE: Collection Assessment in «Medicine»

The purpose of this memo is to provide you with some information about that part of the library collection dealing with "Medicine». Attached to this memo you will find a listing of titles within the Dewey call number range of "610". The listing is arranged in order by highest use. We hope you will assist us in the library by going through the list and indicating which titles (if any) you believe should be withdrawn and/or replaced.

\section{In virtually all of the fields assessed so far, faculty have been fascinated to learn what is being used and what is not.}

The library's computer system has been programmed to provide us with some useful data which you may wish to consider as you work with the list. The assessment of this part of the collection was done on "September 14, 1988", and reflects what the collection looked like on that date. Of the « 1,613 " volumes in the broader field of "Health Sciences", there are "504" volumes devoted to "Medicine". And of these «504" volumes, "204» (i.e. " $40.9 \%$ ") have been used (either in the library or loaned from the library) since the computer system was installed in June 1986. There have been " 536 " loans of the used materials, which accounts for " $18.3 \%$ " of the total circulation of « 2,924 » loans within the broader field of «Health Sciences».

The following is some statistical data which characterizes the age of this part of the library collection (based on publication date). Of the «504" volumes in «Medicine», «308» (or «61.1\%») were published in 1978 or before; "91" (or "18.1\%») were published between 1979 and 1982; and «57" ( or " $11.3 \%$ \%) were published in 1983 or after.

As to location of the materials themselves, «398" are in the nonfiction part of the collection (including oversized books); "103" are in the reference collection (including atlases, indexes, and law); and " 3 " are audiovisual materials.

We would be most grateful if you would assist us by answering the questions on the next page. You may also note on the printout some guidelines which we may use in considering new titles for addition in this part of the collection.

The second page of the letter asks the faculty if there are any authors or standard titles missing; if they can recommend any "best books" listings that we should be consulting; or if there are particular topics on which they would like us to focus collection building. Their responses, as well as any comments we believe worth noting based on the faculty meeting we schedule, are stored in the appropriate database record as topic profile information. As a part of the profile, we also store the faculty's estimate of the number of titles they believe we need to collect annually, as well as the average per volume cost for materials in the topic (gleaned from the "Book Trade Research and Statistics" section of the latest edition of the Bowker Annual Library and Book Trade Almanac).

\section{MEETING WITH FACULTY}

The final segment of the process is generally the most time-consuming component: meeting with faculty. We arrange a first meeting through the departmental library advisory committee representative, asking for about a half-hour to make our presentation. We arrive at the meeting prepared with printouts, letters, and any pertinent use statistics gathered for periodical use and ILL. Because instructional faculty are busy people, we generally conclude the first meeting by scheduling a follow-up meeting from two to four weeks in the future at which time we can continue discussions, answer further ques- 
tions occasioned by the materials we have provided, and retrieve the annotated listings.

The focus of the meetings thus far has been to elicit from the instructional faculty what their expectations are relative to student use of the library collection and to enlist their aid with weeding. We explain the data contained in the cover letter, and point out any anomalies in the printouts. In the sciences, faculty have been particularly interested in the age of the collection: titles published over five years ago are automatically suspect unless they are of historical interest. In virtually all of the fields assessed so far, faculty have been fascinated to learn what is being used and what is not. And, of course, there are always surprises, as we learned during the collection assessment for the nursing department. For example, we discovered that several newer editions of some standard works were gathering dust on the shelves while older versions were seeing high circulation. The reason was that reading lists had not been updated. We also found that an important monographic series, Nursing Clinics of North America, was receiving little use. The reason was the library's decision to catalog the series based on the Library of Congress serial record, rather than as separates with subject access to each volume. The set has subsequently been recataloged in hopes of promoting use.

\section{BENEFITS}

We certainly believe we are reaping many of the benefits traditionally attributed to collection assessment: in particular, a better understanding of the strengths and weaknesses in the collection based on actual use as well as a clearer sense of what faculty expect us to collect. Response to the departmental visits and assessment presentations has been uniformly positive. Faculty appreciate the individualized attention and also learn in greater depth about the specific informational resources and services available to them and to their students.

We have come to the same conclusion reported by Mary Bushing in an article on assessment in smaller libraries: "The pro- cess may yield nothing of value for cooperative collection projects on a regional or state level, but the information can be helpful in defining local cooperative collection projects that result in better access to information. At the very least, local library collection can be changed to better serve their users and to be core collections that can stand independently to meet basic information needs." "A natural extension of the process to include cooperative assessment with Longview Public Library may occur when that agency has completed its lengthy retrospective project of assigning call numbers to all of its holdings. An anticipated outcome of shared collection assessment would be the development of cooperative collection development policies, which would likely include both collecting goals and acquisition commitments in both agencies.

\section{Small libraries face special difficul- ties when attempting to engage in collection assessment activities be- cause of the labor-intensive nature of the activity.}

Small libraries face special difficulties when attempting to engage in collection assessment activities because of the laborintensive nature of the activity. When the LCC Library automated, it did so with the expectation that sharing a turnkey system with our public library would enhance public services by improving access to each other's collections. But the outcomes of automation have far exceeded our expectations, providing us with the wherewithal to conduct a manageable and costeffective ongoing collection assessment program. The result is a strong factual basis upon which requests for increased funding can be substantiated. Indeed, we have come to believe that one of the greatest benefits to automation may well lie in the ability it provides us to manage intelligently the growth and development of the collection on a long-term basis. 


\section{REFERENCES AND NOTES}

1. Pacific Northwest Collection Assessment Manual (Portland, Ore.: Fred Meyer Charitable Trust; Library and Information Resources for the Northwest Program, 1986):1.

2. Ibid., p.6.

3. The collection level indicators of the LIRN project range from "0: Out of Scope" to "5: Comprehensive Level" and are intended to be applied as descriptors using the entire possible bibliographic universe as a comparison. The conspectus method of collection evaluation, as well as the LIRN program generally, is well described in Larry R. Oberg, "Evaluating the Conspectus Approach for Smaller Library Collections," College \& Research Libraries 49:187-96 (May 1988).

4. Lower Columbia College, Alan Thompson Learning Resources Center Collection Development Policy (Longview, Wash.: The College, 1988):1.

5. A good description of the collection-centered processes appears in Blaine H. Hall, Collection Assessment Manual for College and University Libraries (Phoenix, Ariz.: Oryx Press, 1985).

6. "Client-centered techniques measure how the collection is used by patrons. Examples of these techniques are circulation studies, interlibrary loan statistics, shelf availability studies, and various user studies," Pacific Northwest Collection Assessment Manual, p.32.

7. The top ten academic library system installers are profiled in Robert A. Walton and Frank R. Bridge, "Automated System Marketplace 1988: Focused on Fulfilling Commitments," Library Journal: 114:41-53 (April 1, 1989).

8. The author contacted each of the vendors by letter, providing a description of the functionality that was being described in this article and requesting that information on report generation capabilities be sent back in writing for inclusion here.

9. Mary Bushing, "Is Collection Assessment Valuable in Small Public \& School Libraries?" Pacific Northwest Collection Assessment \& Development Newsletter 17:1-2 (1988). 